\title{
Capacity study on flexural strengthening of RC beams with Near Surface Mounted helical rib steel wire
}

\author{
Li Huimin, GAO Yan, Ding Yahong \\ School of civil Engineering, Henan Polytechnic University, Jiaozuo 454000, China
}

Keywords: helical rib steel wire; near-surface mounted(NSM); Concrete beams; flexural behavior

\begin{abstract}
Nine beams strengthened with helical rib steel wire near-surface mounted(NSM) in the concrete cover under monotonous loads are tested, and cyclic loading, security, delay and bending deformation of reinforced concrete beams are systematically studied. Test results indicate that NSM helical rib steel wire can overcome the peeling of the strengthening material from externally bonded FRP laminates. Compared with non-strengthened beam. The strengthened beams can significantly improve its ultimate capacity, and the increase could be as much as $130.92 \%$. The suitable failure modes was discussed for the NSM helical rib steel wire on the basis of the theory of concrete structure, and formulas were derived for the bend moment, the ultimate moment. The predicted results agree well with the measured values from the tests of the studies.
\end{abstract}

\section{Introduction}

The technique of strengthening reinforced concrete members with Externally Bonded fiber-reinforced polymer (FRP) has been widely applied in engineering[1-2], but the technique has a basic flaw: it occurred easily debonding failure in binding material layer[3-5] and its price is expensive. To solve the problem, our research group put forward a new strengthening technique of NSM helix rib steel wire in sawed grooves in the concrete cover, instead of FRP sheets. The helix rib steel wire used in this is prestressed rebar with low relaxation and high strength [6-8], which has good anchorage performance and ductility, bargain price than FRP rebar. Now, The research on bearing capacity of RC beams strengthened with near surface mounted helical rib steel wire has just started,)and the calculation has not related rules. Therefore, the paper presents research on bearing capacity of RC beams strengthened with near surface mounted helical rib steel wire, concerning the damage of the under-reinforced beam.

\section{Fundamental Assumption}

Based on the research result and strengthening theory of the beams, these assumptions are as follows:

1) To correspond with the plane-section assumption;

2) Without regard to the tensile strength of the tension zone of the concrete;

3) Stress and strain continuous among the concrete and the longitudinal steel reinforcements, the strengthened material;

4) The relationship of the stress and strain is the linear elastic;

5) The 《Code for design of concrete structures》 (GB50010-2010)was adopted by the curved line relation of the concrete and the rebar.

\section{Analysis of the flexural capacity}

Based on the above basic assumption and the fundamental principle for the concrete of the flexural members, the flexural behavior of reinforced concrete beams strengthened with Near Surface Mounted helical rib steel wire was analyzed.

\section{Calculating of the ultimate bearing capacity}

From the plane-section assumption and the relationship of the stress and strain, the compressive stress of the concrete could be equivalent to the rectangular stress pattern, and the equivalent height of the compressive zone was $x$, and $\alpha_{1}$ was the ratio between strength of the rectangular stress 
pattern and the maximum stress of the concrete on the compressive zone. $T_{c}=\alpha_{1} f_{c} b x$

$$
\varepsilon_{c}=\frac{\varepsilon_{h} x_{0}}{h_{h}-x_{0}} \quad \varepsilon_{s}^{\prime}=\frac{x_{0}-a_{s}^{\prime}}{h_{h}-x_{0}} \varepsilon_{h} \quad \varepsilon_{s}=\frac{h_{0}-x_{0}}{h_{h}-x_{0}} \varepsilon_{h}
$$

According to the basic assumption and the equilibrium condition, $\beta_{1}$ was the coefficient of the equivalent stress pattern of the rectangle. From the rules and regulations, the relationship of the $\mathrm{x}$ and $x_{0}$ was derived:

$$
x=\beta_{1} x_{0}
$$

1) When concrete beams strengthened with 1-2 helical rib steel wires, the strengthened beams would be happened the damage of the under-reinforced beam. The formula of the flexural capacity calculation of the reinforced beam was derived from the equilibrium condition:

$$
M \leq \alpha_{1} f_{\mathrm{c}} b x\left(\frac{\mathrm{x}}{2}-a_{\mathrm{s}}^{\prime}\right)+f_{\mathrm{y}} A_{\mathrm{s}}\left(h_{0}-a_{\mathrm{s}}^{\prime}\right)+f_{\mathrm{h}} A_{\mathrm{h}}\left(\mathrm{h}_{\mathrm{h}}-a_{\mathrm{s}}^{\prime}\right)
$$

2) When concrete beams strengthened with 3 helical rib steel wires, the strengthened beams would be happened the damage of the over-reinforced beam. The formula of the flexural capacity calculation of the reinforced beam was derived from the equilibrium condition:

$$
M \leq \alpha_{1} f_{\mathrm{c}} b x\left(\frac{x}{2}-a_{\mathrm{s}}^{\prime}\right)+E_{\mathrm{s}} \varepsilon_{\mathrm{s}} A_{\mathrm{s}}\left(\mathrm{h}_{0}-a_{\mathrm{s}}^{\prime}\right)+E_{\mathrm{h}} \varepsilon_{\mathrm{h}} A_{\mathrm{h}}\left(h_{\mathrm{h}}-a_{\mathrm{s}}^{\prime}\right)
$$

\section{Analysis of the flexural capacity}

According to the following formula, $\alpha_{1}$ and $\beta_{1}$ from the formula (3) and (4) were obtained [9]:

$$
\begin{aligned}
& \alpha_{1}=\int_{0}^{\varepsilon_{c}} \frac{\sigma_{c}}{f_{c} \varepsilon_{c}} d \varepsilon_{c} \\
& \beta_{1}=1-\frac{\int_{0}^{\varepsilon_{c}} \sigma_{c} \varepsilon_{c} d \varepsilon_{c}}{\varepsilon_{c} \int_{0}^{\varepsilon_{c}} \sigma_{c} d \varepsilon_{c}}
\end{aligned}
$$

By substituting Eq. (1) into Eq. (5), we find

$$
\begin{aligned}
& \alpha_{1}= \begin{cases}\frac{\varepsilon_{c}}{\varepsilon_{0}}-\frac{\varepsilon_{c}^{2}}{3 \varepsilon_{o}^{2}} & 0 \leq \varepsilon_{c} \leq \varepsilon_{0}=0.002 \\
1-\frac{\varepsilon_{0}}{3 \varepsilon_{c}} & \varepsilon_{0} \leq \varepsilon_{c} \leq \varepsilon_{c u}=0.0033\end{cases} \\
& \beta_{1}= \begin{cases}\left(\frac{1}{3}-\frac{\varepsilon_{c}}{12 \varepsilon_{0}}\right) /\left(1-\frac{\varepsilon_{c}}{3 \varepsilon_{0}}\right) & 0 \leq \varepsilon_{c} \leq \varepsilon_{0}=0.002 \\
1-\left(\frac{1}{2} \varepsilon_{c}^{2}-\frac{1}{12} \varepsilon_{0}^{2}\right) /\left(\varepsilon_{c}^{2}-\frac{1}{3} \varepsilon_{c} \varepsilon_{0}\right) & \varepsilon_{0} \leq \varepsilon_{c} \leq \varepsilon_{c u}=0.0033\end{cases}
\end{aligned}
$$

According to the static equilibrium conditions, the height of the compressive zone $(x)$ could be obtained:

$$
\alpha_{1} f_{c} b x+T_{s}^{\prime}=T_{s}+T_{h}
$$

By substituting $x$ into Eq. (3), (4), we can obtain the bearing capacity from the all kinds of failure mode.

\section{Experimental Verification}

Reinforced beams were designed to be rectangular simply supported beam, the beam cross-section was $150 \mathrm{~mm} \times 300 \mathrm{~mm}$ with a beam length of $2400 \mathrm{~mm}$, and its calculation span was $2100 \mathrm{~mm}$; the stirrups at $1 / 3$ of the beam across are provided by using $8 \mathrm{~mm}$ smooth stirrups spaced at $150 \mathrm{~mm}$, and shear reinforcement at $1 / 3$ of the supports are placed at a spacing of $100 \mathrm{~mm}$; the strength grade of the concrete was $\mathrm{C} 30$, the groove sizes and reinforcement drawing is shown in Fig.1. 


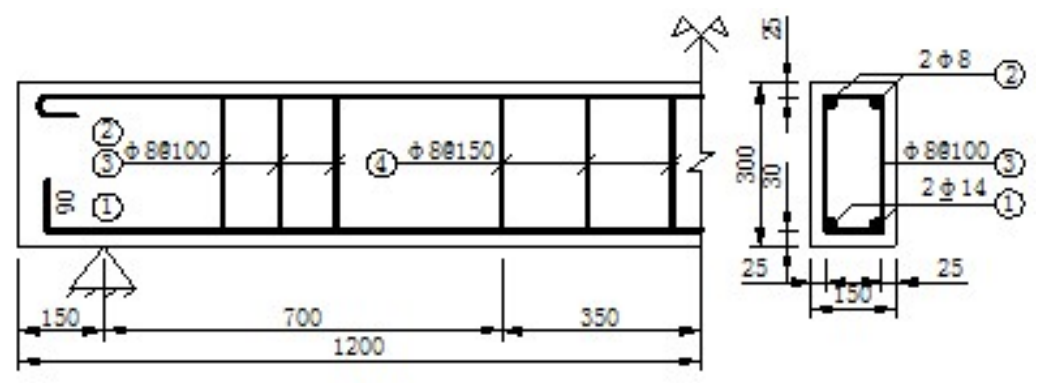

Fig.1 Section spacing and rebar reinforcement configuration of test specimens

The reinforcement is prestressed helix rib steel wire with low relaxation, and its diameter is $7.00 \mathrm{~mm}$. The concentrated load is exerted by a distributive girder in the mid-span of the test beam. In this test, 10 test beams were designed, including one control beam (DB) and nine reinforced beams (BS). Effective specimens of every reinforcing scheme were 3 beams.

\section{Contrast the calculated value with experimental value}

According to the formula from the text, the cracking load, yield load and ultimate load were obtained, and the comparison between the calculated value and the experimental value is shown in Table 1. From the Table 2, we can see that the average ratio is 1.087 , and the error is very small, the result is matching.

Tab.1 Comparison of the computation results and the test results

\begin{tabular}{|c|c|c|c|c|}
\hline \multirow{2}{*}{ Beam number } & \multicolumn{2}{|c|}{ Ultimate load $P_{u} / \mathrm{kN}$} & \multirow{2}{*}{$P_{u} / P_{u}^{\prime}$} & \multirow{2}{*}{ the average } \\
\hline & the average $P_{u} / \mathrm{kN}$ & the calculated value $P_{u} / \mathrm{kN}$ & & \\
\hline DB & 91.73 & 90.68 & 0.988 & \multirow{4}{*}{1.087} \\
\hline BS1 & 133.68 & 143.04 & 1.07 & \\
\hline $\mathrm{BS} 2$ & 172.02 & 190.94 & 1.10 & \\
\hline BS3 & 211.82 & 232.8 & 1.09 & \\
\hline
\end{tabular}

\section{The analysis of significant values for load}

The actual observed value of the cracking load $P_{c r}$, yield load $P_{y}$, limit load $P_{u}$ of the test beam and the load value increases compared with DB beam were shown in table 3. The yield load value is combined with the deformation curves of the test beam and the measured strain of the steel.

\section{Tab.2 Significant values for load}

\begin{tabular}{|c|c|c|c|c|c|c|}
\hline Beam & $\boldsymbol{P}_{\mathbf{c r}} / \mathbf{k N}$ & improve/\% & $\boldsymbol{P}_{\mathbf{y}} / \mathbf{k N}$ & improve/\% & $\boldsymbol{P}_{\mathbf{u}} / \mathbf{k N}$ & improve/\% \\
\hline DB & 20.51 & --- & 86.4 & --- & 91.73 & ---- \\
\hline BS1 & 23.17 & 12.97 & 91.32 & 5.69 & 133.68 & 45.73 \\
\hline BS2 & 23.56 & 14.87 & 111.83 & 29.43 & 172.02 & 87.53 \\
\hline BS3 & 23.78 & 15.94 & 116.45 & 34.78 & 211.82 & 130.92 \\
\hline
\end{tabular}

From the table, cracking load of the BS series (BS1, BS2, and BS3) reinforced concrete beams increased respectively $12.97 \%, 14.87 \%, 15.94 \%$. The influence of the cracking load on helix rib steel wire was very small and it could enhance 10\%.The yield load of the BS series reinforced concrete beams increased respectively $5.69 \%, 29.43 \%, 34.78 \%$, the yield load of the strengthening beams increase with the strengthening amount increasing. When the strengthening amount was small, improved degree was obvious; conversely, when the strengthening amount was bigger, improved degree was small. Thus, the influence of NSM helical rib steel wire on yield loads of reinforced beams was limited to a certain extent. Ultimate load of the BS series reinforced concrete beams increased respectively $45.73 \%, 87.53 \%, 130.92 \%$. The influence of NSM helical rib steel wire on the ultimate loads of reinforced beams was obviously, and the ultimate load was increased with the strengthening amount.

\section{Parameter analyses}

Based on the research findings, the security, ductility and deformation capacity of the beams strengthened with spiral rib steel were analyzed

\section{Safety performance and ductility analysis}

Cracking load Pcr, yield load Py and the deflection $\Delta \mathrm{y}$, ultimate load $\mathrm{Pu}$ and the deflection $\Delta \mathrm{u}$ of 
the reinforced concrete beam were shown in table 3 .

1) Safety performance of concrete beams can be represented for $\mathrm{P}_{\mathrm{u}} / \mathrm{P}_{\mathrm{y}}$. The ratio $\mathrm{P}_{\mathrm{u}} / \mathrm{P}_{\mathrm{y}}$ is larger, the safety performance and ductility of test beams are better; conversely, the ratio $\mathrm{P}_{\mathrm{u}} / \mathrm{P}_{\mathrm{y}}$ is smaller, the safety performance and ductility of test beams are worse.

2) Displacement ductility coefficient of concrete beams $\mu=\Delta_{\mathrm{u}} / \Delta_{\mathrm{y}} . \Delta_{\mathrm{Y}}$ is the mid-span deflection of concrete beams in yield state. $\Delta_{\mathrm{u}}$ is the mid-span deflection of concrete beams in ultimate state. When the failure mode of test beam was marked by concrete crushing, $\Delta_{\mathrm{u}}$ is the mid-span deflection of concrete beams in ultimate load of the $80 \%$. When the failure mode of test beam was marked by spiral rib steel wire broken or yield, $\Delta_{\mathrm{u}}$ is the mid-span deflection of concrete beams in ultimate load.

Tab.3 Safety and ductility coefficient

\begin{tabular}{|c|c|c|c|c|c|c|}
\hline Beam & $p_{y} / \mathrm{kN}$ & $P_{\mathrm{u}} / \mathrm{kN}$ & $P_{\mathrm{u}} / P_{\mathrm{y}}$ & $\Delta_{\mathrm{y}} / \mathrm{mm}$ & $\Delta_{\mathrm{u}} / \mathrm{mm}$ & $\Delta_{\mathrm{u}} / \Delta_{\mathrm{y}}$ \\
\hline DB & 86.4 & 91.73 & 1.06 & 5.74 & 30.24 & 5.3 \\
\hline BS1 & 91.32 & 133.68 & 1.46 & 5.12 & 28.97 & 5.65 \\
\hline BS2 & 111.83 & 172.02 & 1.53 & 6.24 & 26.75 & 4.28 \\
\hline BS3 & 116.45 & 211.82 & 1.81 & 5.65 & 23.25 & 4.12 \\
\hline
\end{tabular}

From the table 3, the $\mathrm{Pu} / \mathrm{Py}$ values of $\mathrm{BS}$ series beam were as follows: $1.46,1.53$, and 1.81 , we can obtain that NSM helical rib steel wire can enhance the safety performance of reinforced beams. Ductility coefficient values can be seen from table 3, the ductility coefficient of DB beam is 5.30 , BS series beam: $5.85,4.28,4.12$, we can see that the ductility requirement could be satisfied; as the strengthening amount increasing, stiffness of reinforced concrete beams were improved, and ductility was gradually reduced.

\section{Deformation analysis}

The features of reinforced concrete beam in mid-span deflection changes with loads were reflected by Load-deflection curves. The load-deflection curve of reinforced concrete beam strengthened with helical rib steel wire was shown in Figure 2.

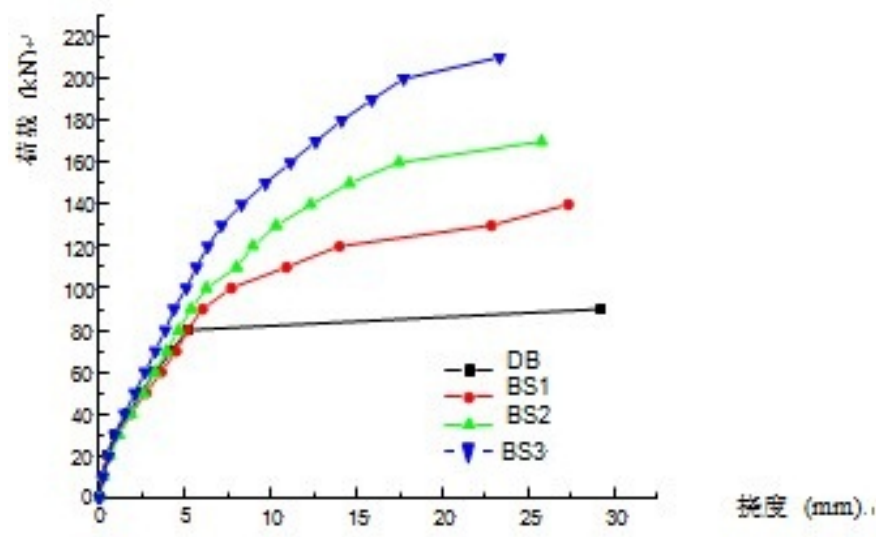

Fig.2 Load-midspan deflection curves

First stage: due to smaller load, reinforced concrete beams showed as elastic deformation, the load and reinforced beam deformation are stable linear growth. The stiffness of BS beam is slightly larger than the DB beam, and the deflection is smaller; the deformation of reinforced concrete beam has a tendency to accelerate near the cracking load.

Second stage: the reinforced concrete beam is similar with DB beam, section of the beam once cracked, then the load-deflection curve suddenly turned, but reinforced concrete beam turned less, and stiffness of reinforced concrete beam has improved significantly compared to DB beam, level of increase is relevant with the strengthening amount, the stiffness of reinforced concrete beam increased greatly when the strengthening amount is larger.

Third stage: the deformation curves turned again and changed largely. The load of DB beam increased slightly and had large deformation [10] until the failure of beams, because of the yield of steel. After the steel yielding, spiral rib steel wire has to share part of its load-deflection curve of turning point is relatively small, throughout part III stage of test load beams with deformation of the 
increase is still rising, and along with the amount of reinforcement increases, the stiffness and bearing capacity of reinforced concrete beams were increased, but the deformation decreases relatively.

\section{Conclusions}

In view of the theoretical analysis and contrastive test, the conclusions were obtained:

1) The debonding damage was effectively avoided by reinforced concrete beam strengthened with spiral rib steel wire, and the behavior of components was improved. The bearing capacity of reinforced concrete beams was significantly increased; the maximum can be increased by $130.92 \%$.

2) The security of reinforced concrete beams was significantly increased by beams strengthened with spiral rib steel wire; ductility requirements of component were met and the deformation was small.

3) Flexural bearing capacity formula and ultimate bearing capacity formula of reinforced concrete beam strengthened with spiral rib steel wire under right rib failure modes were studied, and the calculated values and experimental results of the bearing capacity matched better. Therefore, this theoretical calculation formula can be used for reinforcement design of practical engineering.

To sum up, the reinforced concrete beam strengthened with helical rib steel wire is a very economic and effective reinforcement method; this technique provided theoretical foundation and experimental basis for strengthening method in practical engineering application.

\section{Acknowledgment}

Foundation items:Natural Science Foundation of China(51108161); provincial key disciplines project of Henan (509919); Doctoral Fund of Henan Polytechnic University (B2010-10).

\section{References}

[1] Yue Qingrui. Present status of research and application of strengthening and repairing technology with carbon fibre reinforced plastics (CFRP) and its outlook in china [J]. Industrial construction, 2000, 30(10):23-26.

[2] China Association for Engineering Construction Standardization. CECS146, Technical specification for strengthening concrete structures with carbon fiber reinforce polymer laminate[S]. Beijing: China Planning Press, 2003.

[3] Teng Jinguang.FRP reinforced concrete structure [M].Beijing: China Building Industry Press, 2005.

[4] Tian Shui, Gu Qian. Research on forced performance of RC beams strengthened with prestressed CFRP [J]. Industrial construction, 2005,35(6):88-91.

[5] Zeng Xiantao.The experimental study of concrete beams strengthened with near-surface mounted CFRP[R].Henan polytechnic university, 2006.

[6] Wang Xuezhi. The effect of spiral rib steel wire shape and size[J].Metalware, 1999(2):22-24.

[7] Zhou Yuhui, Xu Changduo. Development and Application of concrete strengthened with prestressed spiral rib steel wire [J]. Metalware, 1997(2):11-13.

[8] The People's Republic national standards-PC steel Wire. Beijing: China Building Industry Press, 2002-10-01

[9] Teng Zhiming. Basic members of reinforced concrete[M].Qinghua university press, 1999, 41-59.

[10] Song Xianrui. Experimental research on flexural performance of reinforced beam strengthened with carbon fiber cloth in initial load [J].Master degree thesis of Zhengzhou University, 2007. 